\title{
Diagnostic and therapeutic laparoscopy in the management of endometriosis
}

\author{
Sujata Swain ${ }^{1 *}$, Paresh Kumar Jena²
}

\begin{abstract}
${ }^{1}$ Department of Obstetrics and Gynaecology, SCB Medical College Cuttack, Odisha, India
${ }^{2}$ Department of Internal Medicine, Kalinga Hospital, Bhubaneswar, Odisha, India
\end{abstract}

Received: 11 September 2018

Accepted: 06 October 2018

\author{
*Correspondence: \\ Dr. Sujata Swain, \\ E-mail: drsujata74@gmail.com
}

Copyright: (c) the author(s), publisher and licensee Medip Academy. This is an open-access article distributed under the terms of the Creative Commons Attribution Non-Commercial License, which permits unrestricted non-commercial use, distribution, and reproduction in any medium, provided the original work is properly cited.

\begin{abstract}
Background: Endometriosis associated with a variety of symptoms, primarily produces dysmenorrhea and infertility. Three classes of techniques have been used to diagnose women with endometriosis beside the history and the clinical picture: biochemical markers, radiological imaging and laparoscopic examination of peritoneal cavity.

Methods: All 52 patients were evaluated clinically, biochemically, and radiologically and laparascopically to find out the abnormalities.

Results: Most common complaint in a patient with endometriosis is dysmenorrhea affecting $67.6 \%$ population in this study group. $20 \%$ patients presented with infertility. Diagnostic laparoscopy of the patients in the study group show ovarian endometrioma in $67.3 \%$ population. Stage II endometriosis was seen in maximum number of cases in the study group comprising $46.2 \%$ patients. Ovarian cystectomy was the most common therapeutic procedure done in $51.9 \%$ of patients, out of which $40.4 \%$ cases treated with unilateral cystectomy and rest by bilateral cystectomy.

Conclusions: This study concludes that endometriosis predominantly affects the women of reproductive age group and causes dysmenorrhea and infertility in majority of the patients. A laparoscopic finding marks as a standard tool in diagnosis and treatment of endometriosis.
\end{abstract}

Keywords: Diagnostic laparoscopy, Dysmenorrhea, Endometriosis, Infertility, Ovarian cystectomy

\section{INTRODUCTION}

Endometriosis predominantly affects women of reproductive age and is associated with pelvic pain (dysmenorrhea, chronic pelvic pain, dyspareunia) and/or infertility but can be asymptomatic. ${ }^{1}$

Endometriosis is characterized by the presence of functioning endometrial glands and stroma together outside the uterine cavity. It is thought to be a relatively common disease with an estimated prevalence among women of reproductive age as high as 10 percent. Endometriosis although associated with a variety of symptoms, primarily produces pain and infertility. Three classes of techniques have been used to diagnose women with endometriosis beside the history and the clinical picture: biochemical markers, radiological imaging and laparoscopic examination of peritoneal cavity. Diagnostic laparoscopy in endometriosis

Most guidelines state that laparoscopic visualization of suspicious lesions is the gold standard for the definitive diagnosis of endometriosis. During diagnostic laparoscopy, the pelvic and abdominal cavity should be systematically investigated for the presence of endometriosis. Characteristic findings include typical "powder-burn" or "gun-shot" lesions on the serosal surfaces of the peritoneum. These lesions are black, dark brown or bluish nodules or small cysts containing old hemorrhage surrounded by a variable degree of fibrosis 
Endometriosis can appear as subtle lesions also called "atypical" lesions including red implants (petechial, vesicular, polypoid, hemorrhagic, red flame like), serous or clear vesicles and sometimes white plaques or scarring, yellow-brown discoloration of the peritoneum and tuboovarian adhesions.

Table 1: Energy sources in endometriosis surgery.

\begin{tabular}{|c|c|}
\hline Type of energy & Example \\
\hline Mechanical & Hydrodissection, Cutting forceps \\
\hline Electrical & $\begin{array}{l}\text { Electrocautery (monopolar and } \\
\text { bipolar), Vessel sealer (Enseal or } \\
\text { Ligasure) }\end{array}$ \\
\hline Ultrasonic & $\begin{array}{l}\text { Cavitational aspirator, Harmonic } \\
\text { scalpel, Piezo-electric transducer, } \\
\text { Microwave ablation, } \\
\text { Radiofrequency ablation }\end{array}$ \\
\hline Laser & $\begin{array}{l}\text { Nd-YAG laser, Argon beam } \\
\text { coagulator }\end{array}$ \\
\hline
\end{tabular}

Deeply invasive endometriosis is associated with reduced depth and volume of the pouch of Douglas suggesting that this phenotype of endometriosis does not develop in the recto-vaginal septum but is the consequence of intraperitonealy buried anterior rectal wall adhesions.

Ovarian endometriotic cysts are usually located on the anterior surface of the ovary and are often associated with retraction, pigmentation and adhesions to the posterior peritoneum. These ovarian endometriotic cysts often contain a thick, viscous dark-brown fluid (chocolate fluid) composed of hemosiderin derived from previous intraovarian haemorrhage

\section{Therapeutic laparoscopy in endometriosis}

The aim of the surgery is to destroy or remove areas of endometriosis, removing the ovarian endometriotic cysts, cutting away or excising the cyst capsule or opening the cyst, draining the chocolate fluid and destroying the capsule and dividing adhesions to free tissues to reduce pain and improve fertility.

\section{Laser ablation}

The word laser stands for Light Amplification by Stimulated Emission of Radiation. There is a thin beam of concentrated light that is an intense energy beam that burns endometriotic tissues. There are different types of lasers including carbon dioxide, YAG, Argon or Diode. The laser is very precise, is able to access difficult areas and produces less damage to surrounding tissues. It seals blood vessels and can minimise bleeding.

\section{Electrocoagulation}

This is the use of electrical heat as used in general surgery. It can be used to destroy and remove endometriosis as well as control bleeding. Study suggests that very less number of patients experience endometriosis pain after electrocoagulation.

\section{Excision surgery}

This involves actually cutting out areas of endometriosis using micro scissors. Endometriomas are generally removed by excision process.

Excision of endometriotic cyst is often referred as "cystectomy". This reduces recurrence of endometriosis but most of the times damage the outer layer of ovary that contains egg.

\section{Fulguration}

This is a procedure to destroy endometriotic tissue using a high frequency electric spark more than 10,000 per second by a needle like electrode. Endometriotic lesions are ablated from base as similar to cauterization.

\section{Helica thermal coagulation}

This uses Helium gas and a small electric current to dry out endometriosis using a process similar to fulguration.

\section{Ultrasonic aspiration}

The instrument is commonly known as CUSA (cavitron ultrasonic surgical aspirator). This is a device with a vibration tip and can be used in the treatment of endometriosis.

\section{Adhesiolysis}

Endometriosis may be very severe that leads to adhesion of pelvic organs forming a "Frozen Pelvis". Laparoscopically these adhesions can be separated. In addition, the carbon dioxide which is used to inflate the abdomen provides a natural separation of pelvic organs.

\section{Vaporization}

It is the insicion or dissection of the tissue by converting it to gas using the laser energy.

\section{Peritoneal Endometriosis}

A small RCT by Wright showed that excision and ablation equally improved pelvic pain associated with mild endometriosis. A more recent RCT including women with all stages of endometriosis showed that ablation was as effective as excision. ${ }^{2}$ Ablation and excision of peritoneal disease are thought to be equally effective for treatment of endometriosis-associated pain. Ovarian endometriosis: A Cochrane review by Hart and co-workers reviewed two RCTs comparing laparoscopic excision of ovarian endometriotic cysts $>3 \mathrm{~cm}$ diameter to drainage and coagulation by bipolar diathermy. ${ }^{3}$ Both studies demonstrated lower recurrence of dysmenorrhea 
and dyspareunia after cystectomy compared to drainage and coagulation only. A more recent RCT that was not included in the Cochrane review compared cystectomy with $\mathrm{CO}_{2}$ laser vaporization. This showed that recurrence of cysts was more common at 12 months, but not at 60 months, after laser vaporization and that the time to recurrence was shorter compared to cystectomy. ${ }^{4}$

The objectives of this study are to know distribution of pelvic endometriosis in relation to age group and socioeconomic status, extent of endometriosis and the chance of infertility associated with it; to know the common symptoms and clinical presentations of endometriosis and to know in detail the role of laparoscopy in the diagnosis and treatment of endometriosis.

\section{METHODS}

This study was undertaken in the Department of Obstetrics and Gynaecology, SCB Medical College, Cuttack, Odisha within a period of two years from January 2016 to December 2017.

\section{Sources of data}

52 Eligible patients having endometriosis who fulfil the study entry criteria attending to $\mathrm{O}$ and $\mathrm{G}$ Department, SCB Medical College, Cuttack were prospectively recruited after being given informed consent to participate in the study.

\section{Methodology}

All patients were evaluated clinically, biochemically, and radiologically to find out the abnormalities and to find out any etiology. Patient undergone diagnostic laparascopy to confirm the diagnosis and to have ASRM staging of disease. Therapeutic laparascopy performed in ASRM stages II, III, IV Patients were followed up for period of three month.

\section{Diagnostic laparoscopy in endometriosis}

Hospital admission is just for a day care surgery. The patient gets operated under a general anaesthesia. Before the anaesthetic the patient must have nothing to eat or drink for at least 6 hours. The hospital gives detailed information to the patient about this prior to the operation. At the start of the operation, the bladder is emptied or catheterised. A veress needle is then inserted just close to the umbilicus and the abdomen is filled with carbon dioxide gas. The gas flow is carefully monitored throughout. The carbon dioxide gas lifts the abdominal wall away from the bowel to make introduction of the laparoscope safer. Two other small incisions may be made as per the requirement. A careful inspection is made of the uterus, ovaries, fallopian tubes, pouch of Douglas, bowel, bladder and all surrounding areas and a record of the severity of the disease were made.

\section{Therapeutic laparoscopy in endometriosis}

For surgery to treat endometriosis, one or two further small incisions made on the abdomen. This is for the introduction of other instruments required for holding tissues, destroying or removing endometriosis, washing tissues, sucking out smoke, blood or washing fluid. Procedure conducted are Ovarian cystectomy (unilateral and bilateral), adhesiolysis, Fulguration of endometriotic nodules, salpingoophorectomy, hysterectomy. At the end of the operation, the small cuts will be closed with a stitch. The stitches can be removed after a few days.

\section{RESULTS}

In the present study most, common age group found to be affected by endometriosis are in the range of 31-35 years comprising $32.69 \%$ of the study population followed by 26-30 years age group comprising $30.77 \%$.

Table 2: Age distribution.

\begin{tabular}{|lll|}
\hline Age group & Number & Percentage \\
\hline $21-25$ & 10 & 19.24 \\
\hline $26-30$ & 16 & 30.77 \\
\hline $31-35$ & 17 & 32.69 \\
\hline $36-40$ & 6 & 11.54 \\
\hline$>40$ & 3 & 5.76 \\
\hline
\end{tabular}

Third most common age group are 21-25 years comprising $19.24 \%$. Very less number of people aged above 35 years are affected by endometriosis (Table 2).

Table 3: socioeconomic status.

\begin{tabular}{|lll|}
\hline Ses & Number & Percentage \\
\hline Lower & 14 & 26.9 \\
\hline Lower middle & 20 & 38.5 \\
\hline Upper middle & 14 & 26.9 \\
\hline Upper & 4 & 7.7 \\
\hline
\end{tabular}

In this study $65.4 \%$ of total patients belong to middle socioeconomic status, whereas $26.9 \%$ from low socioeconomic status and only $7.7 \%$ belong to high socioeconomic status (Table 3).

Table 4: Chief complains.

\begin{tabular}{|lll|}
\hline Chief complain & Number & Percentage \\
\hline Dysmenorrhea & 44 & 67.6 \\
\hline Dyspareunia & 4 & 6.2 \\
\hline Infertility & 13 & \\
\hline Primary & 8 & 20.0 \\
\hline Secondary & 5 & \\
\hline Chronic pelvic pain & 4 & 6.2 \\
\hline
\end{tabular}

Most common complaint in a patient with endometriosis is dysmenorrhea affecting $67.6 \%$ population in this study group. $20 \%$ patients presented with infertility. Out of 13 
patients, 8 were having primary infertility and 5 were having secondary infertility. Least common complaint was dyspareunia and chronic pelvic pain comprising $6.2 \%$ each (Table 4$)$.

Table 5: Diagnostic laparoscopy.

\begin{tabular}{|lll|}
\hline D-lap finding & Number & Percentage \\
\hline Ovarian endometrioma & & \\
\cline { 1 - 2 } Right & 13 & \\
\hline Left & 12 & 67.3 \\
\hline Bilateral & 10 & \\
\hline Adhesions & 16 & 30.8 \\
\hline Endometriotic nodules & 17 & 32.7 \\
\hline
\end{tabular}

Diagnostic laparoscopy of the patients in the study group show ovarian endometrioma in $67.3 \%$ population. Right sided endometrioma in 13 patients, left sided in 12 patients and bilateral involvement in 10 patients. Peritoneal adhesions were present in $30.8 \%$ population and endometriotic nodules were present in $32.7 \%$ population in the study group (Table 5).

Table 6: ASRM staging.

\begin{tabular}{|lll|}
\hline ASRM staging & Number & Percentage \\
\hline I (minimal) & 15 & 28.8 \\
\hline II (mild) & 24 & 46.2 \\
\hline III (moderate) & 11 & 21.2 \\
\hline IV (severe) & 2 & 3.8 \\
\hline
\end{tabular}

Stage II endometriosis was seen in maximum number of cases in the study group comprising $46.2 \%$ patients. Second most common finding was stage I comprising $28.8 \%$. Third most common is stage III with $21.2 \%$ and least common is stage IV with $3.8 \%$ (Table 6). Most common associated pathology with endometriosis in this study group was found to be hydrosalpinx comprising $11.6 \%$ cases.

Table 7: Associated lesions.

\begin{tabular}{|lll|}
\hline Associated lesion & Number & Percentage \\
\hline Adenomyosis & 2 & 3.8 \\
\hline Fibroid & 3 & 5.8 \\
\hline Hydrosalpinx & 6 & \\
\hline Unilateral & 4 & 11.6 \\
\hline Bilateral & 2 & \\
\hline Cervical stenosis & 3 & 5.8 \\
\hline Septate uterus & 2 & 3.8 \\
\hline
\end{tabular}

Out of 6 patients with hydrosalpinx, 4 had unilateral and 2 had bilateral involvement. Fibroid uterus and cervical stenosis were seen in 3 patients each. Only 2 patients presented with adenomyosis and septate uterus each (Table 7).

Ovarian cystectomy was the most common therapeutic procedure done in $51.9 \%$ of patients, out of which $40.4 \%$ cases treated with unilateral cystectomy and rest by bilateral cystectomy. Second most common procedure was bipolar coagulation comprising $38.5 \%$ population and third most common was adhesiolysis comprising $30.8 \%$ population. Fulguration of endometriotic nodules were done in $21.1 \%$ cases and simple puncture with drainage in $7.7 \%$ cases. 6 cases treated with salpingoophorectomy (4 cases unilateral and 2 cases bilateral) and 7 cases out of 52 needed hysterectomy (Table 8).

Table 8: Therapeutic laparoscopy.

\begin{tabular}{|lll|}
\hline Therapeutic lap & Number & Percentage \\
\hline Cystectomy & & \\
\hline Unilateral & 21 & 40.4 \\
\hline Bilateral & 6 & 11.5 \\
\hline Simple puncture & 4 & 7.7 \\
\hline Adhesiolysis & 16 & 30.8 \\
\hline Bipolar coagulation & 20 & 38.5 \\
\hline Fulguration & 11 & 21.1 \\
\hline Salpingoophorectomy & & \\
\hline Unilateral & 4 & 7.7 \\
\hline Bilateral & 2 & 3.8 \\
\hline Hysterectomy & 7 & 13.5 \\
\hline
\end{tabular}

Out of total 35 patients with ovarian endometrioma, 27 needed cystectomy comprising $77.2 \%$ population. 4 patients were treated with simple puncture and drainage and rest 4 patients needed oophorectomy comprising $11.4 \%$ each. Total 7 patients out of 52 had undergone Laparoscopy Assisted Vaginal Hysterectomy (LAVH). On first sitting of laparoscopy, they were diagnosed with endometriosis and classified as per ASRM classification. 2 cases were stage II endometriosis and 5 were stage III. Then they were treated with 2 or 3 doses of Injection Leuprolide (3.75mg) i.m. and again planned for therapeutic laparoscopy. On second sitting, 5 had undergone LAVH and rest 2 undergone LAVH with Bilateral SalpingoOphorectomy (BSO). 3 cases had fibroid uterus.

\section{DISCUSSION}

\section{Age}

Rajeswari $\mathrm{M}$ et al studied that $68 \%$ patients are between the age of 26-35 years, high frequency were reported in the age group 26-30 (37\%). ${ }^{4}$ Latika S. et al stated that $69.3 \%$ patients with endometriosis belong to $25-35$ years age group. ${ }^{5}$ In the present study, most common age group affected are 26-35 year consisting around $63.46 \%$ population and 21-35 years consisting around $19.24 \%$. (Table 2)

\section{Socioeconomic Status}

Arumugam K. stated that there is no association between occurance of endometriosis and social class distribution. ${ }^{6}$ 
Latika S. et al stated that $53.8 \%$ patient with endometriosis belong to lower middle class and $38.5 \%$ to upper middle class. ${ }^{5}$ In the present study lower middle socio-economic status comprise $38.5 \%$ cases and lower and upper middle class comprise $26.9 \%$ each. So, there is no association between endometriosis and socioeconomic status (Table 3).

Clinical symptoms: Giudice LC7 et al stated that most common symptom of endometriosis is pain just before and during periods. ${ }^{7}$ About $59.5 \%$ patients present with dysmenorrhea. In the present study, $67.7 \%$ cases presented with dysmenorrhea followed by infertility. So, dysmenorrhea is the most common presenting symptom in endometriosis (Table 4).

\section{Association with infertility}

ASRM stated that up to $30-50 \%$ women with endometriosis may experience infertility. Mishra V8. et al studied $48.38 \%$ patients with infertility have endometriosis (180 out of 372). ${ }^{8}$ Meuleman $\mathrm{C}$ et al studied that the prevalence of endometriosis in women with infertility is as high as $30 \% .^{9}$ In the present study 13 infertile patients were seen in total of 52 . So, prevalence of infertility in endometriosis is around $25 \%$ (Table 4).

\section{Site of endometriosis}

Diagnostic laparoscopy in endometriosis David Molloy studied that ovary is the most common site affected in endometriosis. It is also found on the peritoneum of the pelvis, posterior surface of uterus and rarely involves bladder and bowel.

Latika $\mathrm{S}$ et al stated that ovary is involved in all the 13 cases of endometriosis followed by POD (84.6\%) and post. surface of uterus $(15.4 \%) .{ }^{5}$ Mishra $\mathrm{V}$ et al stated that laparoscopy is gold standard for the diagnosis of endometriosis. ${ }^{8}$

Ovary is the most common site in endometriosis as per the present study (35 out of 52) followed by posterior culde-sac. Unilateral ovarian involvement is seen in 25 cases (13 right sided and 12 left sided) and bilateral in 10 cases (Table 5). In the present study all the cases of endometriosis were confirmed by laparoscopy.

Therefore, laparoscopy is gold standard for the diagnosis of endometriosis. Visual inspection of the pelvis can establish a definitive diagnosis.

\section{ASRM staging}

Ramirez D. et al studied that stage II disease affects about $55.9 \%$ patients (57 out of 102 cases) and stage IV affects only $10.8 \%$ cases. Rajeswari M. et al studied that stage III disease is most prevalent in all age groups and least is stage IV. ${ }^{4}$ Mishra V. et al stated that stage I disease affects $66.1 \%$ patients with endometriosis. ${ }^{8}$ In the present study stage II disease is most prevalent (46.2\%) and least is stage IV (3.8\%) (Table 6).

\section{Associated lesion in endometriosis}

Latika $\mathrm{S}$ et al studied that fibroid is associated with $23 \%$ cases of endometriosis followed by hydrosalpinx (7.6\%). ${ }^{5}$ Matalliotakis et al stated that uterine anomaly affects 13 patients out of 425 patients with endometriosis i.e. $3.05 \% .^{10}$

In the present study, hydrosalpinx is present in $11.6 \%$ patients followed by fibroid $(5.8 \%)$. Adenomyosis and septate uterus include $3.8 \%$ each (Table 7 ).

\section{Therapeatic laparoscopy in endometriosis}

Mishra $\mathrm{V}$ et al stated that minimal and mild endometriosis are treated by fulguration or cauterization, but moderate and severe cases treated by endometrioma excision and adhesiolysis. ${ }^{8}$

Willy Davila G. stated that drainage or laparoscopic cystectomy is most common procedure used for ovarian endometrioma. ${ }^{11}$

In present study, lap cystectomy done in $51.9 \%$ patients followed by electrocautery in $38.5 \%$ cases, adhesiolysis in $30.8 \%$ cases and fulguration in $21.1 \%$ cases (Table 8 ).

\section{CONCLUSION}

Endometriosis should be suspected in any woman of reproductive age who presents with dysmenorrhoea or chronic pelvic pain. Only laparoscopy can reliably identify endometriosis. If endometriosis is diagnosed at the time of laparoscopy, laparoscopic surgery should be the first choice of treatment, especially in women of reproductive age with an endometriomata. In women with endometriomata, the cystectomy, instead of drainage and ablation should be considerd. Every effort should be made to treat endometriosis actively at first laparoscopy with aim of complete removal of all visible lesions. Therapeutic Laparoscopic surgery has a lot to offer in infertile women with moderate to severe endometriosis. Though surgical treatment is technically demanding but patient rewarding.

\section{Funding: No funding sources \\ Conflict of interest: None declared}

Ethical approval: The study was approved by the Institutional Ethics Committee

\section{REFERENCES}

1. Andrew S. Cook. Pathophysiology of endometriosisassociated infertility. Clin Obstet Gynecol. 2017;42(3):586-610. 
2. Healey M, Ang WC and Cheng C. Surgical treatment of endometriosis: a prospective randomized double blinded trial comparing excision and ablation. Fertil Steril. 2010;94(7):2536-40.

3. Hart RJ, Hickey M, Maouris P and Buckett W. Excisional surgery versus ablative surgery for ovarian endometriomata. Cochrane Database Syst Rev 2008(2).

4. Rajeswari M, Ramanidevi T, Kadalmani B. Cohort study of endometriosis in south Indian district. Int $\mathrm{J}$ Reprod Contracept Obstet Gynecol. 2016;5(11):3883-8.

5. Sahu L, Tempe A. Laparoscopic management of endometriosis in infertile women and outcome. Int $\mathrm{J}$ Reprod Contracept Obstet Gynecol. 2016;2(2):17781.

6. Arumugam K, Lim JM. Menstrual characteristics associated with endometriosis. BJOG: An International Journal of Obstetrics and Gynaecology. 1997 Aug;104(8):948-50.

7. Giudice LC. Clinical practice. Endometriosis. N Engl J Med. 2010;362(25):2389-98.
8. Mishra VV, Gaddagi RA, Aggarwal R, Choudhary S, Sharma U, Patel U. Prevalence; characteristics and management of endometriosis amongst infertile women: a one-year retrospective study. J Clinic Diagnos Res: JCDR. 2015;9(6):QC01.

9. Koninckx PR, Meuleman C, Demeyere S, Lesaffre E, Cornillie FJ. Suggestive evidence that pelvic endometriosis is a progressive disease, whereas deeply infiltrating endometriosis is associated with pelvic pain. Fertil Steril. 1991;55(4):759-65.

10. Matalliotakis IM, Goumenou AG, Matalliotakis M, Arici A. Uterine anomalies in women with endometriosis. J Endomet. 2010;2(4):213-7.

11. Davil GW, Estape R. Gynecologic laparoscopy surgical oncology. Clinic North Am. 2001;10(3):557-70.

Cite this article as: Swain S, Jena PK. Diagnostic and therapeutic laparoscopy in the management of endometriosis. Int J Reprod Contracept Obstet Gynecol 2018;7:4695-700. 